NBER WORKING PAPER SERIES

\author{
INFLATION FORECAST TARGETING: \\ IMPLEMENTING AND MONITORING \\ INFLATION TARGETS
}

Lars E. O. Svensson

Working Paper 5797

\author{
NATIONAL BUREAU OF ECONOMIC RESEARCH \\ 1050 Massachusetts Avenue \\ Cambridge, MA 02138 \\ October 1996
}

I have benefitted from discussions with and/or comments from Larry Ball, Claes Berg, Larry Christiano, Guy Debelle, Hans Dillén, Neil Ericsson, Jon Faust, Stanley Fischer, Marvin Goodfriend, Andrew Haldane, Mervyn King, Hans Lindberg, David Mayes, Stefan Mellin, Frederic Mishkin, Stefan Palmqvist, Torsten Persson, Glenn Rudebusch, Jürgen von Hagen, participants in seminars at the IIES, the CEPR-Banco de España European Summer Symposium on Macroeconomics, the Board of Governors, the Federal Reserve Bank of New York, the 1996 ISOM in Vienna, especially the discussants Kenneth Rogoff and Guido Tabellini, as well as the editors and two anonymous referees. I thank Charlotta Groth for research assistance, and Maria Gil and Christina Lönnblad for editorial and secretarial assistance. This paper is part of NBER's research programs in International Finance and Macroeconomics and Monetary Economics. Any opinions expressed are those of the author and not those of the National Bureau of Economic Research.

(C) 1996 by Lars E. O. Svensson. All rights reserved. Short sections of text, not to exceed two paragraphs, may be quoted without explicit permission provided that full credit, including $\mathbb{O}$ notice, is given to the source. 


\title{
INFLATION FORECAST TARGETING: IMPLEMENTING AND MONITORING \\ INFLATION TARGETS
}

\begin{abstract}
Inflation targeting is shown to imply inflation forecast targeting: the central bank's inflation forecast becomes an explicit intermediate target. Inflation forecast targeting simplifies both implementation and monitoring of monetary policy. The weight on output stabilization determines how quickly the inflation forecast is adjusted towards the inflation target. Money growth or exchange rate targeting is generally inferior to inflation targeting and leads to higher inflation variability. Commitment to "target rules" may be more effective than commitment to "instrument rules."
\end{abstract}

Lars E. O. Svensson

Institute for International Economic Studies

Stockholm University

10691 Stockholm

SWEDEN

and NBER

lars.svensson@iies.su.se 


\section{Introduction}

In recent years a number of countries (New Zealand, Canada, U.K., Sweden, Finland, Australia and Spain) have instituted explicit inflation targeting. An inflation targeting regime has several characteristics. The crucial one is a quantitative inflation target, typically 2 percent per year. In most cases there is also an explicit tolerance interval around the inflation target, typically \pm 1 percentage point. Finally, there is no explicit intermediate target, such as a money growth target or an exchange rate target (except for Spain which, as a participant of ERM, also has an exchange rate target). As argued in Leiderman and Svensson (1995, Introduction) the last characteristic is not crucial; (temporary) intermediate targets are not inconsistent with an inflation target, as long as the inflation target has priority if a conflict arises. ${ }^{1}$

The purpose of this paper is to examine inflation targeting with regard to potential problems with its implementation by the monetary authority and its monitoring by the public and market agents. Inflation targeting has some obvious general advantages, and some potentially serious problems. The general advantages focusing monetary policy directly on achieving the goal of low and stable inflation. With a specified quantitative target, it provides an ex post measurement of monetary policy performance, namely realized inflation relative to the inflation target. It also provides measurement of the credibility of monetary policy, in the form of measures of inflation expectations relative to the inflation target. Both these measurements simplify the evaluation of monetary policy and thereby the accountability of monetary policy is increased. By increasing accountability, inflation targeting may serve as a potential commitment mechanism, reduce or eliminate any inflation bias (for instance, due to the reasons examined in Barro and Gordon (1983)) and increase the likelihood of achieving and maintaining low and stable inflation, as well as anchoring and stabilizing inflation expectations.

More specifically, as demonstrated in Svensson (1996c), in a framework where discretionary monetary policy leads to an inflation bias (for instance due to an implicit employment target that exceds the natural rate of employment, as in Barro and Gordon (1983)), a low inflation target may also reduce or even remove the inflation bias. In some cases it may lead to the same equilibria as the linear inflation contracts proposed by Walsh (1995) and extended by Persson and Tabellini (1993), but be relatively easier to implement. Since a low inflation target need not distort the relative output/inflation variability, 'inflation-target conservative' goals (that is,

\footnotetext{
${ }^{1}$ See the papers in Leiderman and Svensson (1995) and Haldane (1995), as well as Ammer and Freeman (1995) and McCallum (1995), for discussion of and details on inflation targeting.
} 
with a lower inflation target) for the central bank may lead to better equilibria than Rogoff's (1985) 'weight conservative' goals for the central bank (that is, with a higher weight on inflation stabilization).

However, inflation targeting faces some potentially serious problems with regard to both its implementation and its monitoring. First, inflation targeting may be difficult to implement, for the simple reason that central banks have imperfect control over inflation. Current inflation is essentially predetermined by previous decisions and contracts, which means that central banks can only affect future inflation. 'Long and variable lags', and variable strength in the effect of monetary policy on future inflation make decisions on current instrument setting inherently difficult. Inflation is also affected by other factors than monetary policy, in particular disturbances that occur within the 'control lag' between the instrument change and the resulting effect on inflation. Second, the imperfect control over inflation makes monitoring and evaluation of monetary policy by the public inherently difficult. For instance, with a control lag of 1.5-2 years, it appears that current monetary policy cannot be evaluated until realized inflation has been observed 1.5-2 years later. However, that observed inflation is the result of several other factors than monetary policy, in particular disturbances that monetary policy cannot respond due to the control lags. Thus, measuring monetary policy performance is not straightforward. A central bank may argue that a particular deviation of realized inflation from the inflation target is due to factors outside its control, and that it should hence not be held accountable for the deviation.

With implementation, monitoring and evaluation made more difficult, accountability improves less, and the potential commitment mechanism is correspondingly weakened. Sceptics and critics may argue that the merits of inflation targeting are highly dubious, and that less sophisticated money growth targeting or exchange rate targeting is a safer way to achieve low inflation. $^{2}$

This paper argues that the potentially serious problems with implementing and monitoring inflation targeting have a simple but powerful solution. Inflation targeting implies inflation forecast targeting: The central bank's inflation forecast becomes an intermediate target. ${ }^{3}$ Making

\footnotetext{
${ }^{2}$ Cf. von Hagen (1996).

3 The idea that long lage imply that forecaets should be targeted rather than current values goes back at least to Hall (1985), and is further discuseod with rogend to nominal GDP targeting in Hall and Mankiw (1990). With regard to explicit inflation forecant targeting, see King (1994, p. 118): “The use of an inflation target does not mean that there is no intermediate target. Rather, the intermediate target is the expected level of inflation at some future date chomen to sllow for the lag botween changes in interest rates and the resulting changes in inflation. In practice, we use a forccasting horizon of two yoars." Soe also Bowen (1995, p. 57): "The most appropriate guide to monetary policy [under inflation targeting] is the best obtainable forecast of the probability
} 
this explicit simplifies both implementation and monitoring of monetary policy. The central bank's infiation forecast is indeed an ideal intermediate target: it is by definition the current variable that is most correlated with the goal, it is more controllable than the goal, and it can be made more observable than the goal. It can also be made very transparent, and may therefore facilitate the central bank's communication with the public, and the public's understanding of monetary policy. In (rare) special cases when either money growth targeting or exchange rate targeting is the optimal arrangement, inflation targeting will automatically imply that arrangement. Very sophisticated money growth targeting can be made equivalent to inflation targeting, but it is much less transparent, whereas simple money growth targeting is inefficient in that it provides more inflation variability than inflation targeting. ${ }^{4}$

The role of output stabilization in inflation targeting is a contentious issue, cf. Fischer (1996) and King (1996b). The paper shows that the weight on output stabilization in the central bank's loss function is directly related to the rate at which inflation is adjusted towards the inflation target. A zero weight on output stabilization implies an instrument setting such that the inflation forecast for the control lag always equals the inflation target. A positive weight implies a gradual adjustment of the inflation forecast towards the inflation target, at a slower rate the larger the weight. With this intuitive result, the issue appears less contentious.

The paper emphasizes the distinction between 'target rules' for intermediate targets and 'instrument rules' for the instrument (the latter proposed by McCallum (1990) and Taylor $(1993,1996 \mathrm{a}, \mathrm{b}))$ and argues that target rules are more effective.

Section 2 of the paper discusses the implementation of inflation targeting and demonstrates, with the help of a very simple model, that inflation targeting implies inflation forecast targeting. Section 3 discusses public monitoring and evaluation of inflation targeting. Section 4 shows that the inflation forecast is indeed an ideal intermediate target. Section 5 discusses the relation

distribution for inflation, over a time borizon defined by how long it takes for a change in monetary policy to affect inflation. Such a forecast must use information from a wide variety of sources. It can be thought of as an intermediate target: monetary policy is to be adjuated to maximize the probability forecant at the time of the policy adjustment -of inflation falling within the target range by the time the adjustment has taken effect."

Clark, Laxton and Rose (1995) emphasize the role of lags in monetary palicy and compare, in a model with a non-linear Phillips curve, myopic and forward-boking decision rules.

'By the central benk's infation forecast I mean the central bank's own 'structural' (model-based) forecast, the forecast besed on its view and (not nocesarily completaly formal) model of the fundamental determinants of infiation and the transmission mechaniam of monetary policy. In particular, the central bank must have a view on the relevant policy multiplier, how the inflation forecant is afiected by the monetary policy instrument. Within a discussion of nominal GDP targeting, Hall and Mankiw (1994) have argued that the central bank should target outside forecasters' consensus forecast (of nominal GDP) rather than its own structural forecast. Woodford (1994) has shown, however, that targeting other forecasters' forecauts is problematic, if these forecasters incorporate in their forocasting procedure the central bank's foedback rule from their forecasts. Instability, multiple equilibria, or even non-existence of equilibria may result. These probloms are avoided if the central bank targets its own structural forecast. 
of inflation targeting to money targeting. Section 6 examines the role of output stabilization. Sections 7 discusses the role of bands for inflation. Section 8 examines the distinction between target rules and instrument rules. Section 9 concludes. Appendices A and B contain some technical points. ${ }^{5}$

\section{Implementing inflation targeting: Inflation forecast targeting}

This section argues that the solution to the potential problem in implementing inflation targeting consists of making the central bank's inflation forecast an explicit intermediate target. Although this is a very straightforward result that hardly requires a model, I believe that it is best demonstrated with the help of a very simple model. Although the result can be demonstrated in a much more elaborate model with an explicit role for agents' expectations, it is sufficient to use a much simpler one in this case. The model nevertheless has some structural similarity to more elaborate models used by some central banks. ${ }^{6}$

Consider therefore the model

$$
\begin{aligned}
\pi_{t+1} & =\pi_{t}+\alpha_{1} y_{t}+\alpha_{2} x_{t}+\epsilon_{t+1} \\
y_{t+1} & =\beta_{1} y_{t}-\beta_{2}\left(i_{t}-\pi_{t}\right)+\beta_{3} x_{t}+\eta_{t+1} \\
x_{t+1} & =\gamma x_{t}+\theta_{t+1}
\end{aligned}
$$

where $\pi_{t}=p_{t}-p_{t-1}$ is the inflation (rate) in year $t, p_{t}$ is the (log) price level, $y_{t}$ is an endogenous variable ((log) output (relative to potential output), say), $x_{t}$ is an exogenous variable, $i_{t}$ is the monetary policy instrument (the repo rate, say), and $\epsilon_{t}, \eta_{t}$ and $\theta_{t}$ are i.i.d. shocks in year $t$ that are not known in year $t-1$. The coefficients $\alpha_{1}$ and $\beta_{2}$ are assumed to be positive; the other coefficients are assumed to be nonnegative; $\beta_{1}$ and $\gamma$ in addition fulfill $\beta_{1}<1, \gamma<1$. The change in inflation is increasing in lagged output and the lagged exogenous variable. Output is serially correlated, decreasing in the lagged (pseudo-)'real' repo rate, $i_{t}-\pi_{t}$, and increasing in the lagged exogenous variable. The long-run natural output level is normalized to equal zero. The repo rate affects output with a one-year lag, and hence inflation with a two-year lag, the

\footnotetext{
${ }^{5}$ After the first version of the present paper wa written, I received a copy of Haldane (1996), which independently expresees similar ideas together with examples from UK inflation targeting.

- I believe these issues on implementing and monitoring inflation targeting can be discuseod without necessarily assuming the systematic discretionary inflation bies (due to 'timo-consistency' problems) emphasized in the modern 'principal-agent' approach to central banking (for instance in the work by Barro and Gordon (1983), Rogoff (1985), Cukierman (1992), Walsh (1995b), Permon and Tabellini (1993) and Svenmon (1996c)) and disputed in the 'traditional' approach (for instance in McCallum (1995) and Romer and Romer (1996b)); see Tabellini (1995) for discussion of these apprasches. Therefore the model here does not include any source of discretionary inflation bias, although this can easily be added without affocting the results.
} 
control lag in the model. That the instrument affects inflation with a longer lag than it affects output is the crucial property of the model. It is consistent with results from a number of VAR-studies. ${ }^{7}$

Suppose monetary policy is conducted by a central bank with an inflation target $\pi^{*}$ (say 2 percent per year). Interpret inflation targeting as implying that the central bank's objective in period $t$ is to choose a sequence of current and future repo rates $\left\{i_{\tau}\right\}_{\tau=t}^{\infty}$ so as to minimize

$$
\mathrm{E}_{t} \sum_{\tau=t}^{\infty} \delta^{\tau-t} L\left(\pi_{\tau}\right)
$$

where $\mathrm{E}_{t}$ denotes expectations conditional upon (the central bank's) information available in year $t$, the discount factor $\delta$ fulfills $0<\delta<1$, and the period loss function $L\left(\pi_{\tau}\right)$ is

$$
L\left(\pi_{\tau}\right)=\frac{1}{2}\left(\pi_{\tau}-\pi^{*}\right)^{2} .
$$

That is, the central bank wishes to minimize the expected sum of discounted squared future deviations of inflation from the target. ${ }^{8}$

It is crucial here that inflation targeting is interpreted as implying a single goal; that the inflation rate is the only variable in the period loss function (2.5). Svensson (1996c) has argued that inflation targeting may in practice be interpreted by central banks as involving additional goals for output or employment. The consequences of an additional goal of output or employment stabilization are discussed in section 6 . There it is shown that some weight on output stabilization leads to a very intuitive modification of the results.

\footnotetext{
${ }^{7}$ In this annual discrete-time model, the instrument $i_{t}$ can be interpreted as a two-week repo rate that must be held constant throughout each year. Then $i_{\text {i }}$ can alternatively be interpreted as a one-year interest rate that is controlled by the central bank. Then (2.2) is consistent with an aggregate demand equation where output depends on the real one-year interest rate $i_{t}-E_{t} \pi_{t+1}$,

$$
y_{t+1}=\tilde{\beta}_{1} y_{t}-\bar{\beta}_{2}\left(i_{t}-E_{t} \pi_{t+1}\right)+\tilde{\beta}_{3} x_{t}+\epsilon_{t+1},
$$

where the expected inflation rate by (2.1) fulfills

$$
E_{t} \pi_{t+1}=\pi_{t}+\alpha_{1} \nu_{t}+\alpha_{2} x_{t},
$$

and where

$$
\beta_{1}=\bar{\beta}_{1}+\alpha_{1} \tilde{\beta}_{2}, \beta_{2}=\bar{\beta}_{2} \text { and } \beta_{3}=\bar{\beta}_{3}+\alpha_{2} \tilde{\beta}_{2} \text {. }
$$

A more elaborate model would include a long real interest rate in the aggregate demand function and link the long nominal rate to the repo rate via the expectations hypothesis, for instance as in Fuhrer and Moore (1995).

With a more precise terminology, the model has a non-increasing-inflation output level equal to zero. Strictly speaking, cf. McCallum (1989), the model violates the natural-rate hypothesis (of no long-run effect on output or employment of any monetary policy), in that a steady increasing inflation rate permanently increases output. Such policies will never be optimal with the loes functions to be used in this paper. If such policies are attempted, the presumption is that the model would break down.

Since the central bank does not have parfect control over infiation it is not meaningful to minimize the realized squared deviations, only the expected aquarod doviations (conditional upon the information available when the repo rate is set).
} 
Since the repo rate affects inflation with a two-year lag, it is practical to express $\pi_{t+2}$ in terms of year $t$ variables and $t+1$ and $t+2$ disturbances:

$$
\begin{aligned}
\pi_{t+2}= & \left(\pi_{t}+\alpha_{1} y_{t}+\alpha_{2} x_{t}+\epsilon_{t+1}\right)+\alpha_{1}\left[\beta_{1} y_{t}-\beta_{2} i_{t}+\beta_{2} \pi_{t}+\beta_{3} x_{t}+\eta_{t+1}\right] \\
& +\alpha_{2}\left(\gamma x_{t}+\theta_{t+1}\right)+\epsilon_{t+2} \\
= & a_{1} \pi_{t}+a_{2} y_{t}+a_{3} x_{t}-a_{4} i_{t}+\left(\epsilon_{t+1}+\alpha_{1} \eta_{t+1}+\alpha_{2} \theta_{t+1}+\epsilon_{t+2}\right)
\end{aligned}
$$

where

$$
a_{1}=1+\alpha_{1} \beta_{2}, a_{2}=\alpha_{1}\left(1+\beta_{1}\right), a_{3}=\alpha_{1} \beta_{3}+\alpha_{2}(1+\gamma) \text { and } a_{4}=\alpha_{1} \beta_{2}
$$

Since in this simple case the repo rate in year $t$ will not affect the inflation rate in year $t$ and $t+1$, but only in year $t+2, t+3, \ldots$, and the repo rate in year $t+1$ will only affect the inflation rate in year $t+3, t+4, \ldots$, we realize that we can find the solution to the optimization problem by assigning the repo rate in year $t$ to hit, on an expected besis, the inflation target for year $t+2$, the repo rate in year $t+1$ to the inflation target for year $t+3$, etc. Thus, the central bank can find the optimal repo rate in year $t$ as the solution to the simple period-by-period problem

$$
\min _{i_{t}} E_{t} \delta^{2} L\left(\pi_{t+2}\right)
$$

(see appendix $\mathrm{A}$ for details). ${ }^{9}$

The first-order condition for minimizing (2.8) with respect to $i_{t}$ is

$$
\frac{\partial \mathrm{E}_{t} \delta^{2} L\left(\pi_{t+2}\right)}{\partial i_{t}}=\mathrm{E}_{t}\left[\delta^{2}\left(\pi_{t+2}-\pi^{*}\right) \frac{\partial \pi_{t+2}}{\partial i_{t}}\right]=-\delta^{2} a_{4}\left(\pi_{t+2 \mid t}-\pi^{*}\right)=0
$$

where $\pi_{t+2 \mid t}$ denotes $E_{t} \pi_{t+2}$, and where I have used that by (2.6) $\frac{\partial \pi_{t+2}}{\partial i_{t}}=-a_{4}$. It follows that the first-order condition can be written

$$
\pi_{t+2 \mid t}=\pi^{*}
$$

That is, the repo rate in year $t$ should be set so that the forecast of the one-year 'forward' inflation rate from year $t+1$ to year $t+2$, conditional upon information available in year $t$, equals the inflation target. Although a more precise terminology for this forecast would be the one-to-two-year forecast, I shall for simplicity call it the two-year forecast. (It should not be confused with the forecast of the average inflation rate between year $t$ and year $t+2$ ) Thus,

9 The two-year lag makes the result especially easy to represent. Svensen (1996b) discusses the case with a general distributed lag. 
the two-year inflation forecast can be considered an explicit intermediate target. ${ }^{10} 11$

It follows that the inflation targeting loss function (2.5) can be replaced by an intermediate loss function $L^{i}\left(\pi_{t+2 \mid t}\right)$, the inflation forecast targeting loss function

$$
L^{i}\left(\pi_{t+2 \mid t}\right)=\frac{1}{2}\left(\pi_{t+2 \mid t}-\pi^{*}\right)^{2}
$$

Instead of minimizing the expected squared deviations of the future two-year inflation rate $\pi_{t+2}$ from the inflation target as in (2.8), the central bank can minimize the squared deviation of the current two-year inflation forecast $\pi_{t+2 \mid t}$ from the inflation target,

$$
\min _{i_{t}} L^{i}\left(\pi_{t+2 \mid t}\right)
$$

Since the first-order condition is the same, (2.9), the same optimal repo rate results. This is of course a straightforward application of standard certainty-equivalence in linear-quadratic models.

The two-year inflation forecast by (2.6) depends on the current state of the economy, $\pi_{t}, y_{t}, x_{t}$ and the instrument $i_{t}$,

$$
\pi_{t+2 \mid t}=a_{1} \pi_{t}+a_{2} y_{t}+a_{3} x_{t}-a_{4} i_{t}
$$

Setting this equal to the inflation target, (2.9), leads to the central bank's optimal reaction function,

$$
\begin{aligned}
i_{t} & =\frac{1}{a_{4}}\left(-\pi^{*}+a_{1} \pi_{t}+a_{2} y_{t}+a_{3} x_{t}\right) \\
& =\pi_{t}+b_{1}\left(\pi_{t}-\pi^{*}\right)+b_{2} y_{t}+b_{3} x_{t},
\end{aligned}
$$

where I have used (2.7) and

$$
b_{1}=\frac{1}{\alpha_{1} \beta_{2}}, b_{2}=\frac{1+\beta_{1}}{\beta_{2}} \text { and } b_{3}=\frac{\alpha_{1} \beta_{3}+\alpha_{2}(1+\gamma)}{\alpha_{1} \beta_{2}} .
$$

This reaction function is of the same form as the Taylor rule (1993), except that it also depends on the exogenous variable (and that the coefficients generally differ from 0.5 ). The real

\footnotetext{
${ }^{10}$ An alternative objective function for an inflation targeting regime is to maximize the probability that future inflation falls within a symmetric band around the inflation target. With a symmetric probability distribution for future inflation, which is the case in the modal ueed here, this results in the same intermediate target (2.9).

11 Brunner and Meltzer (1967, p. 195) define an ideal indicator (that provides "the most reliable measure of the effect of monetary policy") as the differential (or logarithmic differential) of a social utility function (or a scalar variable monotonically related to the social utility) with respect to the monetary policy instrument. As emphasized by Brunner and Meltzer, both a utility function and a theory of the transmission mechanism is needed for the construction of an ideal indicator. In their framework with output as the goal of monetary policy and a velocity equation as the aggregate demand equation, the sum of the relative change of the adjusted monetary base and relative change of the money multiplier appears as an ideal indicator. In this framework with a specific lose function, Phillips curve, and aggregated demand function, an ideal Brunner-Meltzer indicator appears to

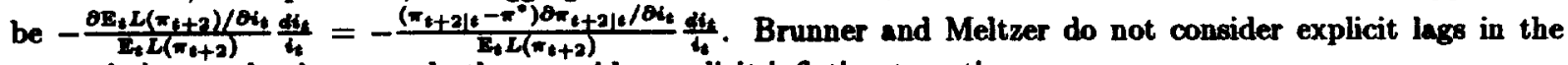
transmiasion mochanism, nor do they consider explicit inflation targeting.
} 
repo rate $i_{t}-\pi_{t}$ is increasing in the excess of current inflation over the inflation target, in current output, and in the current exogenous variable. The instrument depends on current inflation, not because current inflation is targeted (current inflation is predetermined) but because current inflation together with output and the exogenous variable predict future inflation. ${ }^{12}$

With this reaction function the two-year inflation forecast will equal the inflation target, for all values of $\pi_{t}, y_{t}$ and $x_{t}$. If the inflation forecast exceeds (falls short of) the inflation target, the repo rate should be increased (decreased) until the inflation forecast equals the target. If the current inflation rate increases, output increases, or the exogenous variable increases, the repo rate should be increased, in order to keep the inflation forecast equal to the inflation target.

Actual inflation in year $t+2$ will in equilibrium be

$$
\begin{aligned}
\pi_{t+2} & =\pi_{t+2 \mid t}+\epsilon_{t+1}+\alpha_{1} \eta_{t+1}+\alpha_{2} \theta_{t+1}+\epsilon_{t+2} \\
& =\pi^{*}+\epsilon_{t+1}+\alpha_{1} \eta_{t+1}+\alpha_{2} \theta_{t+1}+\epsilon_{t+2}
\end{aligned}
$$

It will deviate from the inflation target and the two-year inflation forecast by the forecast error,

$$
\pi_{t+2}-\pi_{t+2 \mid t}=\epsilon_{t+1}+\alpha_{1} \eta_{t+1}+\alpha_{2} \theta_{t+1}+\epsilon_{t+2}
$$

due to the disturbances that occur within the control lag, after the central bank has set the instrument.

Clearly the central bank cannot prevent deviations from the inflation target caused by disturbances occurring within the control lag. At best it can only control the deviations of the two-year forecast from the target. It can therefore be argued that the central bank should be held accountable for the forecast deviations from the target rather than the realized inflation deviations, if the forecast deviations can be observed.

Equilibrium output will by (2.1), (2.3) and (2.15) be given by

$$
\begin{aligned}
y_{t+1}= & \frac{\pi_{t+2}-\pi_{t+1}-\alpha_{2} x_{t+1}-\epsilon_{t+2}}{\alpha_{1}} \\
= & \frac{\epsilon_{t+1}+\alpha_{1} \eta_{t+1}+\alpha_{2} \theta_{t+1}+\epsilon_{t+2}}{\alpha_{1}} \\
& -\frac{\epsilon_{t}+\alpha_{1} \eta_{t}+\alpha_{2} \theta_{t}+\alpha_{2}\left(\gamma x_{t}+\theta_{t+1}\right)+\epsilon_{t+1}+\epsilon_{t+2}}{\alpha_{1}} \\
= & -\frac{\alpha_{2}}{\alpha_{1}} \gamma x_{t}-\frac{1}{\alpha_{1}} \epsilon_{t}-\eta_{t}-\frac{\alpha_{2}}{\alpha_{1}} \theta_{t}+\eta_{t+1}
\end{aligned}
$$

To generalize from this example, inflation targeting implies a simple rule for its implementation. The central bank's inflation forecast for the horizon corresponding to the control lag (2

\footnotetext{
${ }^{12}$ See Bradbent (1996) for an insightful discussion of Taybor rules in relation to inflation targeting. See also the comment Svenseon (1996a) on Taylor (1996a).
} 
years in the example) becomes an intermediate target, and the instrument should hence be set so as to make the inflation forecast equal to the inflation target. Thus, if the inflation forecast is above (below) the target, the repo rate should be increased (decreased). This simple rule results in the optimal reaction function for the central bank. Since the inflation forecast depends on all relevant information, the instrument will be a function of all relevant information.

Adjusting the instrument so the inflation forecast equals the target is the best the central bank can do. Ex post inflation will differ from the target, because of forecast and control errors, for instance due to disturbances that oocur within the control lag. If the central bank is competent, the mean forecast errors will be zero, and the variance of the forecast errors minimized. Ideally, if the inflation forecast could be verified, the central bank should be accountable for deviations of the inflation forecast from the target, but not for the unavoidable deviations of realized inflation from the target. This issue is discussed further in section 7 .

The central bank's inflation forecast will in practice have to combine both formal and informal components, for instance with judgemental adjustments of more formal structural forecasts. Forecasts will hardly ever be purely mechanical. This view is strengthened by the results of Cecchetti (1995), who has examined mechanical reduced-form inflation forecasts for the United States, with rather negative results. Forecast errors are sizeable, and there are frequent structural shifts in the forecast equations. However, forecast errors for one-year inflation rates, for instance for the one-to-two-year inflation rate emphasized in the model used here, are smaller than for one-quarter inflation rates. As emphasized by Kohn (1995), more structural modeling and use of extramodel information and judgment by forecasters are likely to produce forecasts with acceptable precision. In addition, forecasting inflation is likely to be easier in a situation when the central bank actively pursues inflation targeting and, importantly, the public expects the central bank to pursue inflation targeting so that inflation expectations are stabilized.

\section{Monitoring inflation targeting}

In the model used above, there is no specific need to monitor monetary policy in order to ensure that the central bank implements inflation targeting. If the central bank has the preferences described by (2.4) and (2.5), it will behave according to the optimal reaction function (2.13) with or without monitoring by outsiders. Let me now consider a simple modification of the setup which results in a need for outside monitoring.

Consider the inflation target $\pi^{*}$ in (2.5) as the 'official' explicit inflation target, assigned 
to the central bank by society. Suppose, however, that the central bank has its own implicit inflation target that may deviate from the one assigned by society. More specifically, assume that the central bank has an intertemporal loss function of the form (2.4) with the same discount factor $\delta$ but a time-varying period loss function $L_{t}^{b}\left(\pi_{t}\right)$ given by

$$
\begin{aligned}
L_{t}^{b}\left(\pi_{t}\right) & =\frac{1}{2}\left(\pi_{t}-\pi_{t}^{b}\right)^{2} \\
\pi_{t}^{b} & =\pi^{*}+z_{t} \\
z_{t+1} & =(1-\rho) \bar{z}+\rho z_{t}+\xi_{t+1},
\end{aligned}
$$

where the central bank's implicit inflation target $\pi_{t}^{b}$ deviates from the explicit one, the deviation $z_{t}$ follows an $\operatorname{AR}(1)$ process, the unconditional mean $\bar{z}$ is constant, $|\rho|<1$ and $\xi_{t}$ is i.i.d. A positive unconditional mean $\bar{z}$ may be interpreted as representing a Barro-Gordon (1983) discretionary inflation bias.

The central bank's decision problem then becomes

$$
\min _{i_{t}} E_{t} \delta^{2} L_{t+2}^{b}\left(\pi_{t+2}\right)
$$

The first-order condition is

$$
\frac{\partial \mathrm{E}_{t} \delta^{2} L_{t+2}^{b}\left(\pi_{t+2}\right)}{\partial i_{t}}=-\delta^{2} a_{4}\left(\pi_{t+2 \mid t}-\pi^{*}-z_{t+2 \mid t}\right)=-\delta^{2} a_{4}\left[\pi_{t+2 \mid t}-\pi^{*}-\left(1-\rho^{2}\right) \bar{z}-\rho^{2} z_{t}\right]=0 .
$$

Thus, the first-order condition can be written

$$
\pi_{t+2 \mid t}=\pi^{*}+\left(1-\rho^{2}\right) \bar{z}+\rho^{2} z_{t}
$$

The corresponding reaction function will be

$$
i_{t}=\pi_{t}+b_{1}\left[\pi_{t}-\pi^{*}-\left(1-\rho^{2}\right) \bar{z}-\rho^{2} x_{t}\right]+b_{2} y_{t}+b_{3} x_{t}
$$

where the $b$ coefficients are given by (2.14).

Equilibrium inflation in year $t+2$ will be

$$
\pi_{t+2}=\pi^{*}+\left(1-\rho^{2}\right) \bar{z}+\rho^{2} z_{t}+\epsilon_{t+1}+\alpha_{1} \eta_{t+1}+\alpha_{2} \theta_{t+1}+\epsilon_{t+2}
$$

and equilibrium output will fulfill

$$
\begin{aligned}
y_{t+1} & =\frac{\pi_{t+2}-\pi_{t+1}-\alpha_{2} x_{t+1}-\epsilon_{t+2}}{\alpha_{1}} \\
& =\rho^{2}\left(z_{t}-z_{t-1}\right)-\frac{\alpha_{2}}{\alpha_{1}} \gamma x_{t}-\frac{1}{\alpha_{1}} \epsilon_{t}-\eta_{t}-\frac{\alpha_{2}}{\alpha_{1}} \theta_{t}+\eta_{t+1} .
\end{aligned}
$$


Thus, if the central bank's implicit inflation target deviates from the explicit one by $z_{t}$ in year $t$, the central bank will choose the repo rate so as to set its two-year inflation forecast above the explicit inflation target by $\left(1-\rho^{2}\right) \bar{z}+\rho^{2} z_{t}$, the expected $t+2$ inflation target deviation. Compared to the situation when the central bank shares society's inflation target, the equilibrium inflation in year $t+2$ will deviate by that same amount, and for given $\pi_{t}, y_{t}$ and $x_{t}$, the repo rate in year $t$ will be lower by $b_{1}\left[\left(1-\rho^{2}\right) \bar{z}+\rho^{2} z_{t}\right]$.

Can public monitoring of the central bank prevent these deviations? Suppose the public cannot directly observe the central bank's implicit inflation target $\pi_{t}^{b}$, so that the latter is private information to the central bank. Assume in the simplest case that the public has the same information about the model (2.1)-(2.3) as the central bank, and that the public observes $\pi_{t}, y_{t}, x_{t}$ and $i_{t}$ in year $t$ (and hence can extract the disturbances $\epsilon_{t}, \eta_{t}$ and $\theta_{t}$ ). Even though the public does not directly observe the central bank's inflation target $\pi_{t}^{b}$, it can infer the relevant deviation $\left(1-\rho^{2}\right) \bar{z}+\rho^{2} z_{t}$, either from comparing the current instrument with that corresponding to the optimal reaction function (2.13), or by using (2.12) to form an inflation forecast $\pi_{t+2 \mid t}$ and observe its deviation from the explicit inflation target. (Note that the public need not know the stochastic process (3.3) for the central bank's deviations from the inflation target. $)^{13}$

Thus, the public can spot deviations of the inflation forecast from the explicit inflation target, and by criticizing the central bank for such deviations reduce or even eliminate such deviations (assuming the public agrees with the official inflation target). More specifically, consider such public criticism as equivalent to giving the central bank an additional loss in year $t$ equal to

$$
\varphi L_{t}^{i}\left(\pi_{t+2 \mid t}\right)
$$

where $L^{i}\left(\pi_{t+2 \mid t}\right)$ is given by (2.10) and the parameter $\varphi>0$ measures the intensity of the criticism. Consider further the central bank's behavior in the face of such monitoring as minimizing in year $t$ the total loss

$$
\mathrm{E}_{t} \delta^{2} L_{t+2}^{b}\left(\pi_{t+2}\right)+\varphi L^{i}\left(\pi_{t+2 \mid t}\right)
$$

The first-order condition with respect to $i_{t}$ will be

$$
\delta^{2}\left[\pi_{t+2 \mid t}-\pi^{*}-\left(1-\rho^{2}\right) \bar{z}-\rho^{2} z_{t}\right]+\varphi\left(\pi_{t+2 \mid t}-\pi^{*}\right)=0
$$

hence

$$
\pi_{t+2 \mid t}=\pi^{*}+\frac{\left(1-\rho^{2}\right) \bar{z}+\rho^{2} z_{t}}{1+\varphi / \delta^{2}}
$$

\footnotetext{
${ }^{13}$ Cf. Cukierman and Meltzer (1986) and Faust and Svenseon (1996) for analysis of situations when the central bank preferences cannot be perfectly inferred but instead are eatimated by the public with a Kalman filter.
} 
By intensive criticism, that is, a large $\varphi$, the public can enforce that the central bank's inflation forecast is close to the explicit inflation target. ${ }^{14}$

In the real world, how can the public monitor and evaluate monetary policy with an inflation target? How can the central bank's inflation forecast become observable to the public, so the public can detect deviations from the explicit inflation target? The most effective way to make the central bank's inflation forecast observable to the public and to allow the most thorough monitoring of monetary policy, I believe, is for the central bank to reveal the details of its forecast to the public. This involves revesling the central bank's model, information, assumptions, and judgements in order to allow public scrutiny and discussion of these, including comparison with outsiders' forecasts and analysis. In terms of the model used above, this involves revealing the model (2.1)-(2.3) and its coefficients to the public, as well as the central bank's information about the current state of the economy. Full revelation and public scrutiny is likely to provide the best incentive for high-quality analysis and forecasting by the central bank and to minimize the risk of self-serving bias in the central bank's forecast. An example of this is the increasing occurrence, and increasing quality, of Inflation Reports by inflation targeting central banks, although a fair amount of detail in analysis and assumptions is still kept secret. ${ }^{15}$

Central banks have a strong tradition of secrecy (mostly for no good reasons, I believe). ${ }^{16}$ If an inflation targeting central bank keeps essential components of its inflation forecast secret and thus prevents public observation and scrutiny, there are still ample opportunities to monitor the inflation targeting. Sophisticated observers of monetary policy can, and certainly will, publish their own inflation forecasts and scrutinize monetary policy with the help of these. Less sophisticated observers can always obtain publicly available inflation forecasts by reputable forecasters, for instance in the convenient form of "Consensus Forecasts" already made available by specialized publishers. Such forecasts are frequently published and updated with new information, allowing continuous observation of outsiders' inflation forecasts, even if the central bank is secretive about its forecast.

Central banks can be legally obliged to provide information to the public. It is also possible

\footnotetext{
14 This construction can be interpreted as an inflation contract along the lines of Walsh (1995b) and Persson and Tabellini (1993), where the central bank suffers a coet $\varphi L^{i}\left(\pi_{t+2 \mid t}\right)$ that depends on the inflation forecast.

15 To the extent that the central bank has objectives that deviate from the official ones, it may have an incentive to misrepresent its model and information (in addition to its objectives). The central bank's incentives to misrepresent the truth and mechanism design to onsure trutb-telling is an increasingly relevant subject for future research. See Perseon and Tabellini (1993) and Walah (1995a) for examples of incentive schemes that induce the central bank to reveal the truth.

${ }_{16}$ See Goodfriend (1986) for a classic discussion of secrecy and central banking, and see King (1994) and Haldane (1996) for the role of transparency in U.K. inflation targeting.
} 
for governments to create an independent body, separate from the central bank, that monitors monetary policy. This may be a possibility that has received insufficient attention in discussions of central bank reform.

Thus, outsiders have ample opportunities to monitor and evaluate the central bank's policy, either with the central bank's own analysis and forecast available, or with that of outside forecasters and analysts. In its simplest form, monitoring inflation targeting then consists of observing whether available inflation forecasts are on target or whether they systematically exceed or fall short of the target, in which case the direction (although not the magnitude) of the warranted correction of monetary policy is obvious, since the principles of inflation targeting monetary policy are so simple and transparent.

In most situations the central bank and sophisticated outside observers are likely to have approximately the same information about the state of the economy and approximately similar models. There is no reason for systematic biases in information or models between the central bank and these sophisticated observers. ${ }^{17}$ From this point of view, the example above may be rather realistic. The central bank has a distinct information advantage, though, with regard to the planned future path for the instrument, especially if this is related to implicit monetary policy goals that deviate from the official ones. The current instrument setting is observable to the public, but the central bank's plan for future instrument levels is not. Inflation forecasts for longer horizons than the control lag (that is, horizons longer than 2 years in the example above) will be contingent on expected future instrument settings. This means that there could be systematic differences between the central bank's and outsiders inflation forecasts for longer horizons, depending upon differences between the instrument plan of the central bank and the instrument expectations of the outsiders. For instance, if the central bank's longer term inflation forecast is below outsiders' forecasts, this should correspond to a situation when the central bank plans a less expansionary monetary policy than expected by the outsiders, which in turn should correspond to the central bank having a lower implicit inflation target than the public believes.

The public's consensus expectations about the future repo rate can be inferred from the implicit forward interest rate curve that can be estimsted from money market yield curves or

\footnotetext{
${ }^{17}$ For support of this view from inside Bank of England, wee Briault, Haldane and King (1995). Romer and Romer (1996a), comparing forecast errors of the Federal Reserve and of commercial forecasters, report evidence of an informational advantage of the Federal Reserve, but argue that the most likely explanation for any such advantage is not data availability iteelf but rather that its staf ic better at processing and interpreting information, which is consistent with the fact that Federal Reserve Board commits far more resources to forecasting than even the largest commercial forecasters. Whether the relative commitment of resources to forecasting is the same in other countries is an open question.
} 
directly observed on the futures interest rate market (with due acoount of possible risk premia). ${ }^{18}$ Thus, the central bank can compare its repo rate plan to the forward rate curve for systematic discrepancies. Such discrepancies, along with corresponding discrepancies in inflation forecast, is a symptom of credibility problems, in the sense that the implicit goals of the central bank deviate from the public's estimate of these goals. One possible remedy to such credibility problems is increased revelation of central bank plans and analysis. If the public's expectations about the future repo rate coincide with the central bank's plan for the instrument, but the public's inflation forecasts differ from the central bank's, this is an indication of differences in models or information between the public and the bank. Increased revelation by the central bank about its models and information may also remedy that situation.

Ideally, the central bank's implicit goals coincide with the explicit inflation target, and the public understands the central bank's implicit reaction function and has similar models and information as the bank. Then the bank's instrument plan would be consistent with the forward rate curve and the public's and the bank's inflation forecasts should be similar and equal to the explicit inflation target, both for the horizon corresponding to the control lag and for longer horizons.

More sophisticated evaluation of monetary policy would examine and compare the ex post forecast errors of the central bank and outside forecasts with respect to bias and variance. This requires more than the current few years of data from the inflation targeting regimes, though.

The transparency of inflation forecast targeting might help improve the sometimes deficient state of current monetary policy debate in the media in inflation targeting countries (the debste for instance frequently includes requests for lower interest rates without reference to inflation forecasts, sometimes when inflation forecasts clearly exced targets, cf. the discussion in King (1996a)). Perhaps it would then be more natural for debaters to specify whether they share or have different targets, forecasts, estimates of instrument effects and control lags, etc.

\section{An ideal intermediate target}

A good intermediate target for monetary policy is highly correlated with the goal, easier to control by the central bank than the goal, easier to obeerve by both the central bank and the public than the goal, and transparent so that central bank communication with the public and

\footnotetext{
${ }^{18}$ See for instance Svenseon (1994), Soderlind and Svenseon (1996) and various iasues of Bank of England's Inflation Report for discussion and interpretation of yield curves for monetary policy purposes.
} 
public understanding and prediction of monetary policy is facilitated (cf. Brunner and Meltzer (1967), Friedman (1990) and McCallum (1990)). From this perspective, the central bank's inflation forecast appears to be an ideal intermediate target.

First, the inflation forecast $\pi_{t+2 \mid t}$ is by definition the year $t$ variable that has the highest correlation with $t+2$ inflation, since it minimizes the variance of forecast errors and by (2.12) uses all the relevant information in $\pi_{t}, y_{t}$ and $x_{t}$, rather than an arbitrary subset of the available information.

Second, by definition the inflation forecast $\pi_{t+2 \mid t}$ is more controllable than inflation $\pi_{t+2}$ itself. The effect of the instrument on the inflation forecast is the same as the effect on mean inflation, and the variance of the inflation forecast is less than that of inflation, since the forecast errors (2.16) are subtracted.

Third, the inflation forecast is easier to observe by the central bank than inflation. The forecast $\pi_{t+1 \mid 2}$ is (continuously) observable by the central bank in year $t$, since it depends on year $t$ information; it is not necessary to wait until year $t+2$ to observe realized inflation. Also, realized inflation is affected by additional disturbances. As argued in section 3 , the inflation forecast can also be made observable by the public, either because the central bank reveals its forecast to the public, or because outside forecasters' inflation forecasts are easily accessible. This facilitates outside monitoring of the central bank.

Fourth, inflation forecast targeting is very transparent. Although the construction of the forecast is difficult and resource-demanding, the monetary policy conclusions from a given inflation forecast are straightforward: If the forecast is above (below) the target, monetary policy should be adjusted in a contractionary (expansionary) direction. If the forecast is on target, monetary policy is appropriate. I cannot imagine simpler principles, and I cannot imagine anything easier to explain to the public, or anything more conducive to public understanding of monetary policy.

Inflation forecast targeting also has straightforward implications for how to predict monetary policy. Predicting monetary policy becomes equivalent to predicting future inflation, which implies that the information relevant for predicting monetary policy is precisely the information relevant to predicting inflation.

The transparency of inflation forecast targeting is also likely to focus and motivate the work inside the central bank. It is likely to provide strong incentives to improve the central bank's understanding and structural models of the economy, especially if the central bank chooses or is 
required to make its model, analysis and forecast public. It helps to clarify for what the central bank can, and cannot, be accountable.

\section{Money growth targeting}

Inflation forecast targeting generally uses all relevant information for predicting future inflation. This information may include some measure of the money stock, but normally also other macro variables. In the (rare) special case when future inflation is best predicted by just the growth rate of some money aggregate, that is, money growth is a sufficient statistic for future inflation, inflation forecast targeting will be equivalent to money growth targeting. Similarly, if future inflation for a small open economy is best predicted only by the rate of exchange rate depreciation, inflation targeting will be equivalent to exchange rate (depreciation) targeting. But normally money growth or exchange rate depreciation are not sufficient statistics for future inflation; that is, other information has additional predictive value. Then money growth targeting or exchange rate targeting is inefficient and leads to a worse outcome than inflation forecast targeting. ${ }^{19}$

To illustrate this within the above model, add the following money demand function:

$$
m_{t+1}-p_{t+1}=y_{t+1}-\kappa i_{t}+\nu_{t+1}
$$

where $m_{t}$ is (the log of) some monetary aggregate (M3, say), the income velocity for simplicity is unity, the coefficient $\kappa$ is positive, the repo rate affects money demand with a lag, and $\nu_{t+1}$ is an i.i.d. disturbance.

This formulation takes into account the fact that the monetary aggregate cannot be an instrument of the central bank, in the sense that the central bank does not have perfect control of it. The broader the aggregate, the less control has the central bank. It can even be disputed that such a narrow an aggregate as the monetary base is under complete control of the central bank, cf. Goodhart (1994). In (5.1) above, the central bank can affect the monetary aggregate by affecting the money demand, via the direct lagged effect on money demand of the instrument, the repo rate, and via the indirect effect of the instrument on aggregate demand for output. The supply of money then adjusts to money demand by endogenous adjustment of the monetary base. (The price level in (5.1) is predetermined by (2.1).)

First-difference (5.1), which gives

$$
\mu_{t+1}=\pi_{t+1}+y_{t+1}-y_{t}-\kappa i_{t}+\kappa i_{t-1}+\nu_{t+1}-\nu_{t}
$$

\footnotetext{
${ }^{19}$ See Friodman $(1990,1995)$ for a more general discussion of money growth targeting.
} 
where $\mu_{t+1}=m_{t+1}-m_{t}$ denotes (the) money growth (rate).

Since the repo rate affects money growth with a one-year lag, rewrite $\mu_{t+1}$ in terms of year $t$ variables and $t+1$ disturbences:

$$
\begin{aligned}
\mu_{t+1}= & \pi_{t+1}+y_{t+1}-y_{t}-\kappa i_{t}+\kappa i_{t-1}+\nu_{t+1}-\nu_{t} \\
= & \left(\pi_{t}+\alpha_{1} y_{t}+\alpha_{2} x_{t}+\epsilon_{t+1}\right) \\
& +\left(\beta_{1} y_{t}-\beta_{2} i_{t}+\beta_{2} \pi_{t}+\beta_{3} x_{t}+\eta_{t+1}\right)-y_{t}-\kappa i_{t}+\kappa i_{t-1}+\nu_{t+1}-\nu_{t} \\
= & d_{1} \pi_{t}+d_{2} y_{t}+d_{3} x_{t}-d_{1} i_{t}+\kappa i_{t-1}-\nu_{t}+\left(\epsilon_{t+1}+\eta_{t+1}+\nu_{t+1}\right)
\end{aligned}
$$

where

$$
d_{1}=1+\beta_{2}, d_{2}=\alpha_{1}+\beta_{1}-1, d_{3}=\alpha_{2}+\beta_{3} \text {, and } d_{4}=\beta_{2}+\kappa
$$

The one-year money growth forecast is hence

$$
\mu_{t+1 \mid t}=d_{1} \pi_{t}+d_{2} y_{t}+d_{3} x_{t}-d_{4} i_{t}+\kappa i_{t-1}-\nu_{t}
$$

Eliminate $i_{t}$ between (5.5) and (2.12), and express the two-year inflation forecast in terms of year $t$ variables (aside from the repo rate) and the one-year money growth forecast,

$$
\begin{aligned}
\pi_{t+2 \mid t} & =a_{1} \pi_{t}+a_{2} y_{t}+a_{3} x_{t}-\frac{a_{4}}{d_{4}}\left(-\mu_{t+1 \mid t}+d_{1} \pi_{t}+d_{2} y_{t}+d_{3} x_{t}+\kappa i_{t-1}-\nu_{t}\right) \\
& =f_{1} \pi_{t}+f_{2} y_{t}+f_{3} x_{t}-f_{4} i_{t-1}+f_{6} \nu_{t}+f_{5} \mu_{t+1 \mid t}
\end{aligned}
$$

where

$$
f_{1}=a_{1}-\frac{a_{4} d_{1}}{d_{4}}, f_{2}=a_{2}-\frac{a_{4} d_{2}}{d_{4}}, f_{3}=a_{3}-\frac{a_{4} d_{3}}{d_{4}}, f_{4}=\frac{a_{4} \kappa}{d_{4}} \text { and } f_{5}=\frac{a_{4}}{d_{4}} .
$$

Let $\mu_{t+1 \mid t}^{*}$ denote the one-year money growth forecast that makes the two-year inflation forecast equal to the inflation target and hence fulfills,

$$
\pi^{*}=f_{1} \pi_{t}+f_{2} y_{t}+f_{3} x_{t}-f_{4} i_{t-1}+f_{5} \nu_{t}+f_{5} \mu_{t+1 \mid t}^{*}
$$

This results in

$$
\begin{aligned}
\mu_{t+1 \mid t}^{*} & =\frac{1}{f_{5}}\left(\pi^{*}-f_{1} \pi_{t}-f_{2} y_{t}-f_{3} x_{t}+f_{4} i_{t-1}-f_{5} \nu_{t}\right) \\
& =\pi^{*}-g_{1}\left(\pi_{t}-\pi^{*}\right)-g_{2} y_{t}-g_{3} x_{t}+\kappa\left(i_{t-1}-\pi^{*}\right)-\nu_{t}
\end{aligned}
$$

where

$$
g_{1}=\frac{f_{1}}{f_{5}}, g_{2}=\frac{f_{2}}{f_{6}} \text { and } g_{3}=\frac{f_{3}}{f_{5}}
$$


It follows that we can interpret $\mu_{t+1 \mid t}^{*}$ as a conditional one-year money growth target that depends on the information available in year $t$, in this case on $\pi_{t}, y_{t}, x_{t}, i_{t-1}$ and $\nu_{t}$. The repo rate $i_{t}$ should then be chosen so as to minimize

$$
\mathrm{E}_{t} \frac{1}{2}\left(\mu_{t+1}-\mu_{t+1 \mid t}^{*}\right)^{2}
$$

(subject to (5.3)), or, equivalently, chosen so as to fulfill the first-order condition that the oneyear money growth forecast equals the money growth target,

$$
\mu_{t+1 \mid t}=\mu_{t+1 \mid t}^{*}
$$

Fulfilling (5.10) will imply the reaction function (2.13) and is equivalent to fulfilling (2.9).

Note that money growth targeting implies money growth forecast targeting, for the simple reason that money growth reacts with a lag to the instrument and is imperfectly controlled.

We can also consider an unconditional money growth target, $\mu^{*}$, that is constant over time. We realize from (5.2) and (5.8) that the unconditional money growth target must equal the inflation target,

$$
\mu^{*}=\pi^{*}
$$

in order to cause average inflation to be equal to the target.

Suppose the repo rate is set so as to fulfill the unconditional money growth target,

$$
\pi^{*}=\mu_{t+1 \mid t}=d_{1} \pi_{t}+d_{2} y_{t}+d_{3} x_{t}-d_{4} i_{t}+\kappa i_{t-1}-\nu_{t}
$$

This results in the reaction function

$$
\begin{aligned}
i_{t} & =\frac{1}{d_{4}}\left[-\pi^{*}+d_{1} \pi_{t}+d_{2} y_{t}+d_{3} x_{t}+\kappa i_{t-1}-\nu_{t}\right] \\
& =\pi_{t}+h_{1}\left(\pi_{t}-\pi^{*}\right)+h_{2} y_{t}+h_{3} x_{t}+h_{4}\left(i_{t-1}-\pi_{t}\right)-h_{1} \nu_{t},
\end{aligned}
$$

where

$$
h_{1}=\frac{1}{\beta_{2}+\kappa}, h_{2}=\frac{\alpha_{1}+\beta_{1}-1}{\beta_{2}+\kappa}, h_{3}=\frac{\alpha_{2}+\beta_{3}}{\beta_{2}+\kappa} \text { and } h_{4}=\frac{\kappa}{\beta_{2}+\kappa} .
$$

This reaction function should be compared with the optimal reaction function (2.13). It will result in a different equilibrium, with average inflation equal to $\pi^{*}$, but with more variability of inflation. Due to the persistence of both output and the exogenous variable, there will be persistent deviations of both realized inflation and conditional inflation expectations from the inflation target. The equilibrium will be inefficient, since the intertemporal loss (2.5) will be higher. 
Thus, although the sophisticated conditional money growth targeting (5.10) can achieve the same equilibrium as the optimal reaction function (2.13), it is less direct and less transparent. Its role is only to induce the correct reaction function (2.13). Unconditional money growth targeting (5.11) is perhaps more transparent than the conditional one. It will result in long-run average inflation equal to the target, but inflation and inflation expectations will be more variable and show persistent deviations from the target, and unconditional money growth targeting will hence be inefficient. 20

Can unconditional money growth targeting ever be optimal? Consider the expression for the two-year inflation target as a function of the one-year money growth forecast and year $t$ variables other than the repo rate, (5.6). Consider the special case when

$$
f_{1}=f_{2}=f_{3}=f_{4}=0, f_{5}=1 \text { and } \nu_{t}=0
$$

that is when money growth is a sufficient statistic for future inflation, and when there are no disturbances to money demand. Then unconditional money growth targeting would be optimal. The conditions (5.14) on the $f$-coefficients cannot be fulfilled in the model used here. Nevertheless, if they could be fulfilled (which requires some other transmission mechanism for monetary policy than assumed in the above model), inflation targeting would imply unconditional money growth targeting.

Generally, inflation targeting will imply some simple money growth targeting if and only if such money growth targeting is appropriate.

The previous discussion can be adapted to exchange rate targeting, with similar conclusions. Inflation targeting will automatically imply exchange rate targeting if, and only if, exchange rate targeting is optimal. ${ }^{21}$

\footnotetext{
${ }^{20}$ Bundesbank's money growth targets are formulated from a simple quantity equation relationship, such that the money growth target equals the sum of the implicit inflation target of 2 percent, previously called 'unavoidable' inflation and now called 'normative' inflation, and the capacity growth forecast, lese the forecast of the velocity trend (von Hagen (1925)). In terms of the model used here, both the capacity growth forecast and the velocity trend forecast are zero. Hence, Bundesbank's money growth target in this model correaponds to the unconditional $\mu^{*}$. Thus, adherence to this money growth target would be inefficient. However, as emphasized for instance in von Hagen $(1995,1996)$ and Clarida and Gertler (1996), Bundesbank has a most flexible approach to its money growth target, frequently deviating from the money growth target when the inflation forecast is consistent with the inflation target. This might be interpreted as a somewhat bontransparent attempt to adhere to the conditional money growth target (5.8).

21 See Perseon and Tabellini (1996) for a comparision of inflation targeting, money growth targeting and exchange rate targeting for 'ins' and 'outs' of the EMU.
} 


\section{Output stabilization}

The above results are very straightforward when inflation targeting is interpreted as implying one goal only, in the sense that inflation is the only argument of the period loss function (2.5). If inflation targeting is interpreted as involving additional goals, as in Svensson (1996c), the situation will be somewhat more complicated. Generally, additional goals motivate temporary deviations of the inflation forecast from the inflation target.

Let me consider the case when there are additional stabilization goals with regard to real variables, like output or employment. More specifically, consider a situation when there is a longrun inflation target $\pi^{*}$, but no long-run output target (other than the natural rate of output), since monetary policy cannot affect output in the long run. In the short run, suppose the gosl of monetary policy is to stabilize both inflation and output around the long-run inflation target and natural output rate, respectively. Thus, in the goals for monetary policy, there is a symmetry between inflation and output in the short run, but not in the long run. This situation can be described with a period loss function

$$
L\left(\pi_{t}, y_{t}\right)=\frac{1}{2}\left[\left(\pi_{t}-\pi^{*}\right)^{2}+\lambda y_{t}^{2}\right]
$$

where $\lambda>0$ is the relative weight on output stabilization. The intertemporal loss function is

$$
\mathrm{E}_{t} \sum_{\tau=t}^{\infty} \delta^{\tau-t} L\left(\pi_{\tau}, y_{\tau}\right)
$$

The case examined in previous sections corresponds to $\lambda=0 .{ }^{22}$

Simplify the model by eliminating the effect of the exogenous variable, ${ }^{23}$ that is, set

$$
\alpha_{2}=\beta_{3}=0
$$

Then the model is

$$
\begin{aligned}
& \pi_{t+1}=\pi_{t}+\alpha_{1} y_{t}+\epsilon_{t+1} \\
& y_{t+1}=\beta_{1} y_{t}-\beta_{2}\left(i_{t}-\pi_{t}\right)+\eta_{t+1} .
\end{aligned}
$$

\footnotetext{
${ }^{22}$ Nominal income targeting can of course be examined in this framework. Note that the lag structure makes nominal income targeting a bit awkward and complex, though. Several poesible definitions of (peeudo) nominal GDP, $G_{t}$, are conceivable, the one most convenient given the lag structure perhaps being $G_{t+2}=\pi_{t+2}+\frac{1}{\delta} y_{t+1}$, with the loes function $E_{t} \frac{1}{2} \delta^{2}\left(G_{t+2}-G^{*}\right)$, where $G^{*}$ is the nominal GDP target. Aside from problems with the lag structure, nominal GDP targeting, as always involves a arbitrary constant marginal rate of substitution between inflation (or the price level) and output. See, Svensson (1996b) for further comparision between inflation targeting and nominal GDP targeting.

${ }^{23}$ See Svensson (1996b) for discussion of the role of exogenous variables in inflation targeting with output stabilization.
} 
In appendix B, it is shown that the first-order condition for minimizing (6.2) over the repo rate can be written

$$
\pi_{t+2 \mid t}-\pi^{*}=-\frac{\lambda}{\delta \alpha_{1} k} y_{t+1 \mid t}
$$

where the coefficient $k \geq 1$ is given by

$$
k=\frac{1}{2}\left(1-\frac{\lambda(1-\delta)}{\delta \alpha_{1}^{2}}+\sqrt{\left(1+\frac{\lambda(1-\delta)}{\delta \alpha_{1}^{2}}\right)^{2}+\frac{4 \lambda}{\alpha_{1}^{2}}}\right)
$$

That is, the two-year inflation forecast should equal the inflation target only if the one-year output forecast equals the natural output rate. Else it should exceed the inflation target in proportion to how much the one-year output forecast falls short of the natural output level. The proportionality coefficient, $\frac{\lambda}{\delta \alpha_{1} k}$, is increasing in the relative weight on output stabilization, $\lambda$, and decreasing in the (short-run) inflation/output trade-off, $\alpha_{1}$.

The first-order condition (6.6) can be rewritten in a way that has a more intuitive interpretation. Since by (6.4)

$$
y_{t+1 \mid t}=\frac{1}{\alpha_{1}}\left(\pi_{t+2 \mid t}-\pi_{t+1 \mid t}\right)
$$

we can eliminate $y_{t+1 \mid t}$ and get, after some algebra,

$$
\pi_{t+2 \mid t}=c \pi^{*}+(1-c) \pi_{t+1 \mid t}
$$

where $c$ is given by

$$
c=\frac{\delta \alpha_{1}^{2} k}{\lambda+\delta \alpha_{1}^{2} k}
$$

and fulfills $0<c \leq 1$. Thus, the two-year inflation forecast should equal a weighted average of the long-run inflation target and the one-year inflation forecast. When $\lambda=0, c=1$ and the first-order condition collapees to (2.9).

Thus, when there is some weight on output stabilization, instead of adjusting the two-year inflation forecast all the way to the inflation target, the central bank should let it return gradually to the long-run inflation target. The intuition for this is that always adjusting the two-year inflation forecast all the way to the long-run inflation target, regardless of the one-year inflation forecast, requires more output fluctuations. If there is a positive weight on output stabilization, a gradual adjustment of the two-year inflation forecast towards the long-run inflation target reduces output fluctuations. The higher the weight on output stabilization, the slower the adjustment of the inflation forecast towards the long-run inflation target (the smaller the coefficient $c$, se appendix B). 
Since the one-year output forecast and the two-year inflation forecast fulfill

$$
\begin{aligned}
& y_{t+1 \mid t}=\beta_{1} y_{t}-\beta_{2}\left(i_{t}-\pi_{t}\right) \\
& \pi_{t+2 \mid t}=\pi_{t}+\alpha_{1}\left(1+\beta_{1}\right) y_{t}-\alpha_{1} \beta_{2}\left(i_{t}-\pi_{t}\right),
\end{aligned}
$$

it follows from (6.6) (see appendix B) that the reaction function can be written

$$
\begin{aligned}
i_{t} & =\pi_{t}+\frac{\delta \alpha_{1} k}{\beta_{2} \lambda}\left(\pi_{t+2 \mid t}-\pi^{*}\right)+\frac{\beta_{1}}{\beta_{2}} y_{t} \\
& =\pi_{t}+\tilde{b}_{1}\left(\pi_{t}-\pi^{*}\right)+\tilde{b}_{2} y_{t},
\end{aligned}
$$

where

$$
\tilde{b}_{1}=\frac{c}{\beta_{2} \alpha_{1}} \text { and } \tilde{b}_{2}=\frac{c+\beta_{1}}{\beta_{2}} .
$$

The real repo rate is increasing in the excess of the two-year inflation forecast over the inflation target, (6.10), or in the excess of current inflation over the inflation target, (6.11), in addition to being increasing in output. We see that $\lambda=0(c=1)$ results in $\tilde{b}_{1}=b_{1}$ and $\tilde{b}_{2}=b_{2}$ in the single-goal reaction function (2.13). With a positive weight on output stabilization, the coefficients in the reaction function are smaller.

Output and inflation will in equilibrium, by (6.4), (6.5) and (6.11), obey

$$
\begin{aligned}
y_{t+1} & =-\frac{c}{\alpha_{1}}\left(\pi_{t}-\pi^{*}\right)-c y_{t}+\eta_{t+1} \\
\pi_{t+1}-\pi_{t} & =\alpha_{1} y_{t}+\epsilon_{t+1} \\
& =-c\left(\pi_{t-1}-\pi^{*}\right)-\alpha_{1} c y_{t-1}+\alpha_{1} \eta_{t}+\epsilon_{t+1}
\end{aligned}
$$

We see that both output and inflation are mean-reverting, output towards the natural output level and inflation towards the inflation target.

In summary, some weight on output stabilization motivates a gradual adjustment of the twoyear inflation forecast towards the long-run inflation target. The two-year inflation forecast is brought closer to the long-run inflation target than the predetermined one-year inflation target, but not all the way, in order to reduce output variability. The less weight on output stabilization, the faster the adjustment towards the long-run inflation target. ${ }^{24}$

This case can be interpreted as a variable short-run target for the two-year inflation rate, $c \pi^{*}+(1-c) \pi_{t+1 \mid t}$, that deviates from the long-run inflation target $\pi^{*}$ in proportion to the one-year inflation forecast's deviation from the long-run target.

\footnotetext{
${ }^{24}$ Note that an instrument-smoothing objective would similarly make the inflation forecast temporarily deviate from the inflation target in order to reduce the neceesary instrument change, of. Goodhart (1996) for a recent discussion.

Stevens and Debelle (1995) conduct very intereating simulations on an empirical model of the Australian economy, similar to the model (2.1) - (2.3) with a loes function like (6.1) where interest rate smoothing is added.
} 
Thus, a weight on output stabilization makes inflation targeting more complicated, but not overly so. The central bank has to explain that the inflation forecast is only gradually adjusted towards the long-run target. The outside monitoring of the central bank needs to be somewhat more sophisticated. Inflation targeting remains intuitive and transparent. ${ }^{25}$

\section{The role of bands}

Most inflation targeting regimes have an explicit band for inflation, either in the form of a target band without an explicit inflation point target, or in the form of a band around an explicit inflation (point) target. These bands can potentially be interpreted in several ways. First, one may ask whether inflation is supposed to remain within the band all the time, or most of the time. The announced bands are typically 2 percentage points wide, which together with the imperfect control over inflation makes it rather likely that inflation will sometimes move outside the bands. It may then be more transparent to the public if the central bank explicitly acknowledges this, for instance by announcing that it expects to keep inflation within the band $x$ percent of the time. Apparently, inflation targeting central banks have so far shunned such precise statements. From an analytical viewpoint it seems natural to interpret the bands as a confidence interval, proportional to the unconditional standard deviation of inflation, the square root of the sum of the variance of the conditional expectation of inflation and the variance of the inflation forecast errors.

In addition to bands for realized inflation, we can also consider potential bands for inflation forecasts, for conditional expectations of inflation. Bands for inflation forecasts would then be proportional to the unconditional standard deviation of inflation forecasts.

\subsection{A single goal}

Consider first the situation when inflation targeting is interpreted as a single goal, in the sense that only inflation enters the central bank's loss function. The band for realized inflation is then proportional to the standard deviation of possible deviations of realized inflation from the inflation target, due to uncertainty about, and imperfect control of, future inflation. It indicates an anticipated 'unavoidable' variability of inflation. The bandwidth is proportional to the unconditional standard deviation of the sum of control and forecast errors, but not deviations

\footnotetext{
${ }^{25}$ Since the optimal policy with poeitive weight on output stabilization is thus a steady leaning towards the long-run inflation target, it is very different from the so-called opportunistic approach to disinflation discussed in Orphanides and Wilcox (1996) and Rudebusch (1996).
} 
of the inflation forecast (the intermediate target) from the inflation target, since the inflation forecast should always equal the inflation target with a single goal. In terms of the model, the bandwidth would be proportional to $\sqrt{2 \sigma_{\epsilon}^{2}+\sigma_{\eta}^{2}+\sigma_{\theta}^{2}}$, cf. (2.15).

With a single goal there is hence room for a very narrow band for the inflation forecast at most; in the stylized model above there is a zero band for the inflation forecast.

\subsection{Multiple goals}

With multiple gaals, conscious deviations of the inflation forecast from the inflation target occurs. The band for realized inflation then incorporates the unconditional variance of the deviation of inflation forecasts (short-run inflation targets) from the inflation target (the long-run inflation target), in addition to the variance of forecast errors.

There is hence an implicit band for the inflation forecast, in proportion to the unconditional standard deviation of the inflation forecast, which will be increasing in the weight on additional goals. In the above model, that unconditional standard deviation will be increasing in $\lambda$, the relative weight on output stabilization, but also depend on the other parameters of the problem.

A wide band could then potentially indicate that the central bank has a relatively high $\lambda$ and hence a significant output stabilization goal. A narrow band could indicate a commitment to a low or even zero $\lambda$, cf. the discussion in Svensson (1996c).

\subsection{Accountability}

The band for realized inflation can be used to increase the accountability of the central bank, and the central bank may be subject to sanctions if realized inflation moves outside the band. The most explicit example is New Zealand, where the Governor may then be relieved from his post. As discussed by Walsh (1993), this is an optimal arrangement even though inflation is also subject to disturbances outside the control of the central bank, if only realized inflation and not the actions of the central bank can be observed and verified. The optimal bandwidth can then be chosen so as to achieve the optimal trade-off between type I and type II errors (the Governor is fired (because of unanticipated and unobervable disturbances) even though he/she has chosen the (ex ante) appropriate policy, or the Governor is retained even though he/she has chosen an (ex ante) inappropriate policy).

If the central bank's inflation forecast can be observed and verified, it is better to make sanctions conditional upon a band for the inflation forecast rather than realized inflation, since 
then the noise (and injustice) from unobserved disturbances is eliminated. It remsins to be seen whether a central bank's inflation forecasts can be made so observable and verifiable as to allow sanctions to be conditional on forecssts rather than outcomes. If the amount of private information of the central bank is substantial, this may require rather sophisticated incentive schemes in order to induce the central bank to reveal the necessary information, cf. Persson and Tabellini (1993) and Walsh (1995a). Before these issues are resolved, I believe it is best to base possible sanctions on realized inflation, as in New Zealand, rather than on inflation forecasts.

\section{Target rules v8. instrument rules}

Setting the instrument to make the inflation forecast equal to the inflation target is an example of a target rule which, if applied by the monetary authority, results in an endogenous optimal reaction function expressing the instrument as a function of the available relevant information. This is different from an instrument rule that directly specifies the reaction function for the instrument in terms of current information. In the literature, there are two prominent instrument rules, the McCallum rule for the monetary base, proposed by McCallum in several papers, for instance McCallum (1990), ${ }^{26}$ and the Taylor rule for the federal funds rate, in Taylor (1993, $1996 \mathrm{a}, \mathrm{b})$.

Setting the instrument so as to fulfill the target rules (2.9) or (6.8) results in endogenous instrument rules, (2.13) or (6.11). The above target rules depend only on the parameters in the Phillips curve and the central bank's loss function (the single-goal target rule (2.9) depends only on the long-run inflation target). In contrast, the instrument rules also depend on the aggregate demand function. Therefore, the target rules are less complex and more robust than the instrument rules. In the real world, much different information is relevant to forecast inflation; the instrument rule is in principle a complicated function of all such information, not just a few macrovariables.

Even though I believe instrument rules like the McCallum and Taylor rules are important advances in the theory of monetary policy, I consider a commitment to a target rule to be a more effective arrangement than a commitment to an instrument rule. A target rule focuses on the essential, that is, to achieve the goal, and allows more flexibility in finding the corresponding reaction function. More specifically, with new information about structural relationships, such as

\footnotetext{
${ }^{28}$ Although Goodhart (1994) questions whether the monetary base is under sufficient control of the central bank to qualify as an instrument.
} 
changes in exogenous variables, a target rule implies automatic revisions of the reaction function. A commitment to an explicit instrument rule either requires more confidence in the structural model and its stability, or frequent revision that may be difficult to motivate. Target rules are inherently more stable than instrument rules, and easier to identify, motivate and verify.

\section{Conclusions}

Although inflation targeting has several general advantages, it faces some potentially very serious problems with regard to both its implementation by the monetary authority and its monitoring by the public. Implementation is difficult due to the imperfect control of inflation. Monitoring is difficult since inflation reacts to changes in the monetary policy instrument with long and variable lags, and since inflation is affected by other factors than monetary policy. In order to avoid these problems, inflation targeting can be implemented as inflation forecast targeting, in the sense that the monetary authority's inflation forecast is treated as an explicit intermediate target.

The monetary authority can then implement inflation targeting by simply setting the instrument such that its inflation forecast for a horizon corresponding to the control lag equals the inflation target. Ex post realized inflation will deviate from the inflation forecast due to disturbances that occur within the control lag, but these are beyond the control of the monetary authority. The best the monetary authority can do is to get its inflation forecast equal to the inflation target, which will minimize the squared deviations of realized inflation from the inflation target. In order to avoid the problems of instability, multiplicity and even non-existence of equilibria that Woodford (1994) has emphasized, the intermediate target should be the monetary authority's own forecast (based on the fundamental determinants of inflation, the current state of the economy, and the instrument) and not a consensus forecast of outside observers. In particular, the central bank must have a view of how the forecast is affected by the current instrument.

The public can monitor and evaluate inflation targeting by observing and scrutinizing the monetary authority's inflation forecast, in the favorable situation when the monetary authority reveals the details of its forecast. The public can also use inflation forecasts of other forecasters' forecasts for this purpose, especially if the monetary authority keeps its forecast secret to some extent. A healthy competition is likely to arise between the monetary authority and outside professional or academic forecasters with regard to the quality of the analysis and forecasts. 
Although the construction of inflation forecasts is difficult and demanding, the monetary policy conclusions for a given forecast follow simple and intuitive principles: If the forecast is on target, monetary policy is appropriate. If the forecast is above (below) the target, monetary policy should be tightened (eased). This should improve monetary authority communication with the public, the public's understanding of monetary policy, and the predictability of monetary policy.

The inflation targeting framework is especially straightforward to implement and monitor when it is interpreted as involving a single goal only. With additional goals, like stabilizing output or employment, the inflation targeting framework becomes somewhat more complex, but still very intuitive. It can then be interpreted as having a constant long-run inflation target equal to the announced constant inflation target, and a flexible short-run inflation target which is a weighted average of the long-run inflation target and the predetermined one-year inflation forecast. Put differently, a desire to reduce output variability implies that the inflation forecast adjusted gradually towards the long-run target, at a slower rate the more weight is put on output stabilization. Thus both the implementation and monitoring of inflation targeting becomes a bit more complex, but not overly so.

Setting the instrument to make the inflation forecast equal to the inflation target is an example of a target rule, which is different from an instrument rule that directly specifies the reaction function for the instrument. A target rule may be a more effective arrangement, since it focuses on the essential, that is, to achieve the target, is inherently less complex and more stable, and is therefore easier to identify, motivate and verify.

However, it might be argued that the lack of knowledge, and resulting disagreement, about the appropriate macroeconomic model not only make instrument rules inferior to target rules, but that they may be so substantial as to make both the implementation and monitoring of the target rule proposed here too difficult. Imperfect-knowledge about the model certainly poses a general problem for monetary policy. But the inflation targeting framework outlined above is likely to provide very strong incentives for the monetary authority to improve its understanding of the economy and its control of inflation, especially if the monetary authority chooses or is obliged to reveal its model and analysis in detail to the public. ${ }^{27}$

Generally I find it unlikely that monetary authorities have much private information, relative to sophisticated outside observers, about the state of the economy and the behavior of the economy, but that their private information mostly concerns their own implicit goals and their

\footnotetext{
${ }^{27}$ See Svenseon (1996b) for a discussion of inflation targeting under model uncertainty.
} 
corresponding plans for the future instrument. This is consistent with an important role for outside observers in detecting and preventing monetary authority deviations from explicit goals. However, to the extent that monetary authorities do have private information about the state and behavior of the economy, the issue of their incentives to truthfully reveal their information to the public becomes most important. There seems to be room for considerable future research both on the extent of such private information, and on possible incentive schemes to induce monetary authorities to reveal the truth. ${ }^{28}$

Finally, inflation targeting implicitly or explicitly allows base drift of the price level. The price level then becomes non-stationary and integrated of order one, with price level uncertainty increasing in the forecasting horizon. Price level targeting, which makes the price level stationary and reduces long-term price level uncertainty, has received increased attention in the recent literature, cf. Bank of Cansda (1994). Once central banks have learned to successfully target inflation, more ambitious price level targeting may be both a realistic and desirable alternative. Indeed, in Svensson (1996d) it is demonstrated that price level targeting, counter to conventional wisdom, may actually reduce rather than increase short-term inflation variability.

\section{A Period-by-period optimization}

The problem to choose $\left\{i_{\tau}\right\}_{\tau=t}^{\infty}$ so as to minimize

$$
\mathrm{E}_{t} \frac{1}{2} \sum_{\tau=t}^{\infty} \delta^{r-t}\left(\pi_{\tau}-\pi^{*}\right)^{2}
$$

where each $i_{\tau}$ depends on information available in period $\tau$, can be written as a sequence of one-period problems

$$
\min _{i_{i}} \mathrm{E}_{t} \frac{1}{2} \delta^{2}\left(\pi_{t+2}-\pi^{*}\right)^{2}+\mathrm{E}_{t} \sum_{\tau=t+1}^{\infty} \delta^{\tau-t} \min _{i_{\tau}} \mathrm{E}_{\tau} \frac{1}{2}\left(\pi_{\tau+2}-\pi^{*}\right)^{2},
$$

since $\pi_{\tau+2}$ according to (2.12) can be controlled by $i_{\tau}$ and is not affected by $i_{\tau+1}, i_{\tau+2}, \ldots$ This can for instance be seen from the first-order condition for the problem

$$
\min _{i_{t}} \frac{1}{2} \mathrm{E}_{t} \sum_{\tau=t}^{\infty} \delta^{\tau-t} \cdot\left(\pi_{\tau}-\pi^{*}\right)^{2}
$$

which is

$$
\mathrm{E}_{t} \sum_{\tau=t}^{\infty} \delta^{\tau-t}\left(\pi_{\tau}-\pi^{*}\right) \frac{\partial \pi_{\tau}}{\partial i_{t}}=\sum_{\tau=t+2}^{\infty} \delta^{\tau-t}\left(\pi_{\tau \mid t}-\pi^{*}\right) \frac{\partial \pi_{\tau}}{\partial i_{t}}=0
$$

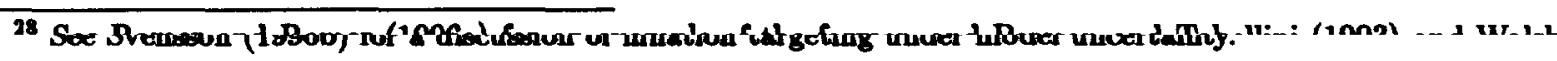


where I have used that $\frac{\partial \pi_{r}}{\partial i_{t}}$ due to the linearity of the model will be constant. Due to (2.12) $i_{t}$ can be chosen such that

$$
\pi_{t+2 \mid t}-\pi^{*}=0
$$

Similarly, $i_{\tau}, \tau=t+1, t+2, \ldots$, can be chooen such that

$$
\pi_{\tau+2 \mid \tau}-\pi^{*}=0
$$

Due to the law of iterated expectations it follows that

$$
\pi_{\tau \mid t}-\pi^{*}=0, \quad \tau=t+3, t+4, \ldots
$$

and the first-order condition (A.3) can be fulfilled with each term in the sum equal to zero. It is clear that this must correspond to a global minimum of the problem. The one-period problem

$$
\min _{i_{\tau}} \delta^{2} \mathrm{E}_{\tau} \frac{1}{2}\left(\pi_{\tau+2}-\pi^{*}\right)^{2}
$$

results in (A.4), so a sequence of one-period problems as in (A.2) will result in the global minimum.

\section{B Output stabilization}

\section{B.1 One-year control lag for inflation}

In order to derive the first-order condition (6.6) it is practical to first study the simpler problem

$$
V\left(\pi_{t}\right)=\min _{y_{t}}\left\{\frac{1}{2}\left[\left(\pi_{t}-\pi^{*}\right)^{2}+\lambda y_{t}^{2}\right]+\delta \mathrm{E}_{t} V\left(\pi_{t+1}\right)\right\}
$$

subject to

$$
\pi_{t+1}=\pi_{t}+\alpha_{1} y_{t}+\epsilon_{t+1}
$$

where output $y_{t}$ is regarded as a control variable.

The indirect loss function $V\left(\pi_{t}\right)$ will be quadratic,

$$
V\left(\pi_{t}\right)=k_{0}+\frac{1}{2} k\left(\pi_{t}-\pi^{*}\right)^{2}
$$

where the coefficients $k_{0}$ and $k$ remain to be determined. The first-order condition is

$$
\lambda y_{t}+\delta \mathrm{E}_{t} V_{\pi}\left(\pi_{t+1}\right) \alpha_{1}=\lambda y_{t}+\delta \alpha_{1} k\left(\pi_{t+1 \mid t}-\pi^{*}\right)=0
$$


where I have used (B.3). This can be written

$$
\pi_{t+1 \mid t}-\pi^{*}=-\frac{\lambda}{\delta \alpha_{1} k} y_{t}
$$

The decision rule for output fulfills

$$
\begin{aligned}
y_{t} & =-\frac{\delta \alpha_{1} k}{\lambda}\left(\pi_{t+1 \mid t}-\pi^{*}\right) \\
& =-\frac{\delta \alpha_{1} k}{\lambda+\delta \alpha_{1}^{2} k}\left(\pi_{t}-\pi^{*}\right)
\end{aligned}
$$

where I have used that by (B.2)

$$
\pi_{t+1 \mid t}=\pi_{t}+\alpha_{1} y_{t}
$$

Then the equilibrium inflation forecast fulfills

$$
\pi_{t+1 \mid t}=\pi_{t}+\alpha_{1} y_{t}=\pi^{*}+\left(1-\frac{\delta \alpha_{1}^{2} k}{\lambda+\delta \alpha_{1}^{2} k}\right)\left(\pi_{t}-\pi^{*}\right)=\pi^{*}+\frac{\lambda}{\lambda+\delta \alpha_{1}^{2} k}\left(\pi_{t}-\pi^{*}\right) .
$$

In order to identify $k$ I exploit the envelope theorem for (B.1) and (B.3) and use (B.5), which gives

$$
V_{\pi}\left(\pi_{t}\right)=k\left(\pi_{t}-\pi^{*}\right)=\left(\pi_{t}-\pi^{*}\right)+\delta k\left(\pi_{t+1 \mid t}-\pi^{*}\right)=\left(1+\frac{\delta \lambda k}{\lambda+\delta \alpha_{1}^{2} k}\right)\left(\pi_{t}-\pi^{*}\right) .
$$

Identification of the coefficient for $\pi_{t}-\pi^{*}$ gives

$$
k=1+\frac{\delta \lambda k}{\lambda+\delta \alpha_{1}^{2} k}
$$

The right-hand side is equal to unity for $k=0$ and increases towards $1+\frac{\lambda}{\alpha_{1}^{2}}$ for $k \rightarrow \infty$. We realize that there is a unique positive solution which fulfills $k \geq 1$. It can be solved analytically:

$$
\begin{gathered}
k^{2}-\left(1-\frac{\lambda(1-\delta)}{\delta \alpha_{1}^{2}}\right) k-\frac{\lambda}{\delta \alpha_{1}^{2}}=0 \\
k=\frac{1}{2}\left(1-\frac{\lambda(1-\delta)}{\delta \alpha_{1}^{2}}+\sqrt{\left.\left(1-\frac{\lambda(1-\delta)}{\delta \alpha_{1}^{2}}\right)^{2}+\frac{4 \lambda}{\delta \alpha_{1}^{2}}\right)}\right. \\
=\frac{1}{2}\left(1-\frac{\lambda(1-\delta)}{\delta \alpha_{1}^{2}}+\sqrt{\left(1-\frac{\lambda(1-\delta)}{\delta \alpha_{1}^{2}}\right)^{2}+\frac{4 \lambda(1-\delta)}{\delta \alpha_{1}^{2}}+\frac{4 \lambda}{\alpha_{1}^{2}}}\right) \\
=\frac{1}{2}\left(1-\frac{\lambda(1-\delta)}{\delta \alpha_{1}^{2}}+\sqrt{\left(1+\frac{\lambda(1-\delta)}{\delta \alpha_{1}^{2}}\right)^{2}+\frac{4 \lambda}{\alpha_{1}^{2}}}\right) \geq 1 .
\end{gathered}
$$




\section{B.2 Two-year control lag for inflation}

After these preliminaries, consider the problem

$$
\min _{i_{i}} E_{t} \sum_{\tau=0}^{\infty} \delta^{\tau} L\left(\pi_{t+\tau}, y_{t+\tau}\right)
$$

subject to

$$
\begin{aligned}
L\left(\pi_{t}, y_{t}\right) & =\frac{1}{2}\left[\left(\pi_{t}-\pi^{*}\right)^{2}+\lambda y_{t}^{2}\right] \\
\pi_{t+1} & =\pi_{t}+\alpha_{1} y_{t}+\epsilon_{t} \\
y_{t+1} & =\beta_{1} y_{t}-\beta_{2}\left(i_{t}-\pi_{t}\right)+\eta_{t+1} .
\end{aligned}
$$

We realize that this can be formulated as

$$
V\left(\pi_{t+1 \mid t}\right)=\min _{y_{t+1 \mid t}}\left\{\frac{1}{2}\left[\left(\pi_{t+1 \mid t}-\pi^{*}\right)^{2}+\lambda y_{t+1 \mid t}^{2}\right]+\delta \mathrm{E}_{t} V\left(\pi_{t+2 \mid t+1}\right)\right\}
$$

subject to

$$
\begin{aligned}
\pi_{t+2 \mid t+1} & =\pi_{t+1}+\alpha_{1} y_{t+1} \\
& =\pi_{t+1 \mid t}+\alpha_{1} y_{t+1 \mid t}+\left(\epsilon_{t+1}+\alpha_{1} \eta_{t+1}\right)
\end{aligned}
$$

where $y_{t+1 \mid t}$ is regarded as the control, and where the optimal repo rate can be inferred from

$$
i_{t}-\pi_{t}=-\frac{1}{\beta_{2}} y_{t+1 \mid t}+\frac{\beta_{1}}{\beta_{2}} y_{t} .
$$

This problem is analogous to the problem (B.1) subject to (B.2). Thus, in analogy with (B.4), the first-order condition can be written

$$
\pi_{t+2 \mid t}-\pi^{*}=-\frac{\lambda}{\delta \alpha_{1} k} y_{t+1 \mid t}
$$

and the reaction function will fulfill

$$
\begin{aligned}
i_{t}-\pi_{t} & =-\frac{1}{\beta_{2}} y_{t+1 \mid t}+\frac{\beta_{1}}{\beta_{2}} y_{t} \\
& =\frac{\delta \alpha_{1} k}{\lambda \beta_{2}}\left(\pi_{t+2 \mid t}-\pi^{*}\right)+\frac{\beta_{1}}{\beta_{2}} y_{t} \\
& =\frac{\delta \alpha_{1} k}{\lambda \beta_{2}}\left[\pi_{t}-\pi^{*}+\alpha_{1}\left(1+\beta_{1}\right) y_{t}-\alpha_{1} \beta_{2}\left(i_{t}-\pi_{t}\right)\right]+\frac{\beta_{1}}{\beta_{2}} y_{t} \\
& =\frac{\delta \alpha_{1} k}{\beta_{2}\left(\lambda+\delta \alpha_{1}^{2} k\right)}\left(\pi_{t}-\pi^{*}\right)+\frac{1}{\beta_{2}}\left(\frac{\delta \alpha_{1}^{2} k}{\lambda+\delta \alpha_{1}^{2} k}+\beta_{1}\right) y_{t}
\end{aligned}
$$

where I have used

$$
\pi_{t+2 \mid t}=\pi_{t}+\alpha_{1}\left(1+\beta_{1}\right) y_{t}-\alpha_{1} \beta_{2}\left(i_{t}-\pi_{t}\right)
$$


and where $k$ will obey (B.6).

Since by (6.4) we have

$$
y_{t+1 \mid t}=\frac{1}{\alpha_{1}}\left(\pi_{t+2 \mid t}-\pi_{t+1 \mid t}\right),
$$

we can eliminate $y_{t+1 \mid t}$ from (B.7) and get, after some algebra,

$$
\pi_{t+2 \mid t}=c \pi^{*}+(1-c) \pi_{t+1 \mid t}
$$

where

$$
0<c=\frac{\delta \alpha_{1}^{2} k}{\lambda+\delta \alpha_{1}^{2} k} \leq 1
$$

The coefficient $\frac{\lambda}{\delta \alpha \hat{k}}$ in (B.7) will be (i) increasing in $\lambda$ and (ii) decreasing in $\alpha_{1}$. Then $c$ in (B.9) will be (i) decreasing in $\lambda$ and (ii) increasing in $\alpha_{1}$. To show (i), consider

$$
z=\frac{k}{\lambda}=\frac{1}{2}\left[\frac{1}{\lambda}-\frac{1-\delta}{\delta \alpha_{1}^{2}}+\sqrt{\left(\frac{1}{\lambda}+\frac{1-\delta}{\delta \alpha_{1}^{2}}\right)^{2}+\frac{4}{\lambda \alpha_{1}^{2}}}\right]=\frac{1}{2}\left[w-A+\sqrt{(w+A)^{2}+4 A B w}\right]
$$

where

$$
w=\frac{1}{\lambda}, A=\frac{1-\delta}{\delta \alpha_{1}^{2}}>0, B=\frac{\delta}{1-\delta}>0 .
$$

It is straightforward to show that $\frac{\partial z}{\partial w}>0$, hence that $\frac{\partial(k / \lambda)}{\partial \lambda}<0$, and $\frac{\partial(\lambda / k)}{\partial \lambda}>0$. To show (ii), consider

$$
v=\alpha_{1} k=\frac{1}{2}\left[\alpha_{1}-\frac{C}{\alpha_{1}}+\sqrt{\left(\alpha_{1}+\frac{C}{\alpha_{1}}\right)^{2}+4 \lambda}\right]
$$

where

$$
C=\frac{\lambda(1-\delta)}{\delta}>0
$$

It is sufficient to show that $\frac{\partial v}{\partial \alpha_{1}}>0$. Thus,

$$
\begin{aligned}
2 \frac{\partial v}{\partial \alpha_{1}} & =1+\frac{C}{\alpha_{1}^{2}}+\frac{2\left(1+\frac{C}{\alpha_{1}^{2}}\right) \alpha_{1}\left(1-\frac{C}{\alpha_{1}^{2}}\right)}{2 \sqrt{\left(\alpha_{1}+\frac{C}{\alpha_{1}}\right)^{2}+4 \lambda}} \\
& =\left(1+\frac{C}{\alpha_{1}^{2}}\right)\left(1+\frac{\alpha_{1}-\frac{C}{\alpha_{1}}}{\sqrt{\left(\alpha_{1}+\frac{C}{\alpha_{1}}\right)^{2}+4 \lambda}}\right) \\
& =\left(1+\frac{C}{\alpha_{1}^{2}}\right) \frac{\sqrt{\left(\alpha_{1}+\frac{C}{\alpha_{1}}\right)^{2}+4 \lambda+\left(\alpha_{1}-\frac{C}{\alpha_{1}}\right)}}{\sqrt{\left(\alpha_{1}+\frac{C}{\alpha_{1}}\right)^{2}+4 \lambda}}>0 .
\end{aligned}
$$

It follows that $c$ decreases monotonically from one towards zero when $\lambda$ goes from zero to infinity. 


\section{References}

[1] Ammer, John, and Richard T. Freeman (1995), "Inflation Targeting in the 1990s: The Experiences of New Zealand, Canada and the United Kingdom," Journal of Economics and Business 47, 165-192.

[2] Bank of Canada (1994), Economic Behavior and Policy Choice under Price Stability, Ottawa.

[3] Barro, Robert, and David Gordon (1983), "A Positive Theory of Monetary Policy in a Natural Rate Model," Journal of Political Economy 91, 589-610

[4] Bowen, Alexander (1995), "British Experience with Inflation Targetry" in Leonardo Leiderman and Lars E.O Svensson, eds., Inflation Targets, CEPR, London.

[5] Briault, Clive B., Andrew G. Haldane and Mervyn A. King (1995), "Independence and Accountability," presented at the VII International Conference, Bank of Japan, October 1995.

[6] Broadbent, Ben (1996), "Taylor Rules and Optimal Rules," Working Paper, Her Majesty's Treasury.

[7] Brunner, Karl, and Allan Meltzer (1967), "The Meaning of Monetary Indicators," in G. Horwich, ed., Monetary Process and Policy, Homewood, mlinois.

[8] Cecchetti, Stephen G. (1995), "Inflation Indicators and Inflation Policy," NBER Macroeconomics Annual 10, 189-219.

[9] Clarida, Richard, and Mark Gertler (1996), "How the Bundesbank Conducts Monetary Policy," NBER Working Paper No. 5581.

[10] Clark, Peter, Douglas Laxton, and David Rose (1995), "Capacity Constraints, Inflation and the Transmission Mechanism: Forward-Looking versus Myopic Policy Rules," Working Paper, International Monetary Fund.

[11] Cukierman, Alex (1992), Central Bank Strategy, Credibility and Independence, MIT Press, Cambridge, MA. 
[12] Cukierman, Alex, and Allan H. Meltzer (1986), "A Theory of Ambiguity, Credibility, and Inflation under Discretion and Asymmetric Information," Econometrica 54, 1099-1128.

[13] Faust, Jon, and Lars E.O. Svensson (1996), "When Credibility Matters: Monetary Policy with Unobserved Targets," in preparation.

[14] Fischer, Stanley (1996), "Why are Central Banks Pursuing Long-Run Price Stability?," forthcoming in Achieving Price Stability, Federal Reserve Bank of Kansas City.

[15] Friedman, Benjamin M. (1990), "Targets and Instruments of Monetary Policy," in Benjamin M. Friedman and Frank H. Hahn, eds., Handbook of Monetary Economics, Volume II, 11851230.

[16] Friedman, Benjamin M. (1995), "The Rise and Fall of Monetary Targeting," presented at the VII International Conference, Bank of Japan, October 1995.

[17] Friedman, Milton (1953), Essays in Positive Economics, Chicago University Press, Chicago.

[18] Fuhrer, Jeffrey C., and George R. Moore (1995), "Monetary Policy Trade-offs and the Correlation between Nominal Interest Rates and Real Output," American Economic Review 85, 219-239.

[19] Goodfriend, Marvin (1986), “Monetary Mystique: Secrecy and Central Banking," Journal of Monetary Economics 17, 63-92.

[20] Goodhart, Charles (1994), "What Should Central Banks Do? What Should Be Their Macroeconomic Objectives and Operations?" Economic Journal 104, 1424-1436.

[21] Goodhart, Charles (1996), "Why Do the Monetary Authorities Smooth Interest Rates?" Special Paper No. 81, LSE Financial Markets Group.

[22] Haldane, Andrew G., ed. (1995), Targeting Inflation, Bank of England, London.

[23] Haldane, Andrew G. (1996), "Some Thoughts on Inflation Targeting," Working Paper, Bank of England.

[24] Hall, Robert E. (1985), "Monetary Strategy with an Elastic Price Standard," in Price Stability and Public Policy: A Symposium Sponsoned by the Federal Reserve Bank of Kansas City, Federal Reserve Bank of Kansas City. 
[25] Hall, Robert E., and N. Gregory Mankiw (1994), "Nominal Income Targeting," in N. Gregory Mankiw, ed., Monetary Policy, University of Chicago Press, Chicago.

[26] King, Mervyn A. (1994), "Monetary Policy in the UK," Fiscal Studies 15, No. 3, 109-128.

[27] King, Mervyn A. (1996a), "Do Inflation Targets Work?" CEPR Bulletin, No. 65, Winter $1995 / 96,4-6$.

[28] King, Mervyn A. (1996b), "How Should Central Banks Reduce Inflation? - Conceptual Issues," forthooming in Achieving Price Stability, Federal Reserve Bank of Kansas City.

[29] Kohn, Donald L. (1995), “Comment," NBER Macroeconomics Annual 10, 227-233.

[30] Leiderman, Leonardo, and Lars E.O. Svensson, eds. (1995), Inflation Targets, CEPR, London.

[31] McCallum, Bennett T. (1990), "Targets, Indicators, and Instruments of Monetary Policy," in William S. Haraf and Phillip Cagan, eds., Monetary Policy for a Changing Financial Environment, The AEI Press, Washington, DC.

[32] McCallum, Bennett T. (1989), Monetary Economics: Theory and Policy, Macmillan, London.

[33] McCallum, Bennett T. (1995), "Inflation Targeting in Canada, New Zealand, Sweden, the United Kingdom, and in General," presented at the VII International Conference, Bank of Japan, October 1995.

[34] Orphanides, Athanasios, and David W. Wilcox (1996), "The Opportunistic Approach to Disinflation," Finance and Economcis Discussion Series No. 96-24, Federal Reserve Board, Washington, D.C.

[35] Persson, Torsten, and Guido Tabellini (1993), "Designing Institutions for Monetary Stability," Carnegie-Rochester Conference Series on Public Policy 39, 53-84.

[36] Persson, Torsten, and Guido Tabellini (1996), “Monetary Cohabitation in Europe," NBER Working Paper No. 5532.

[37] Rogoff, Kenneth (1985), "The Optimal Degree of Commitment to a Monetary Target," Quarterly Journal of Economics 100, 1169-1190. 
[38] Rudebusch, Glenn D. (1996), "Is Opportunistic Monetary Policy Credible?," Working Paper, Federal Reserve Bank of San Francisco.

[39] Romer, Christina, and David H. Romer (1996a), "Federal Reserve Private Information and the Behaviour of Interest Rates," NBER Working Paper No. 5692.

[40] Romer, Christina, and David H. Romer (1996b), "Institutions for Monetary Stability," NBER Working Paper No. 5557.

[41] Sorderlind, Paul, and Lare E.O. Svensson (1996), "New Techniques to Extract Market Expectations from Financial Instruments," Working Paper, IIES.

[42] Stevens, Glenn, and Guy Debelle (1995), "Monetary Policy Goals for Inflation in Australia," in Haldane (1995).

[43] Svensson, Lars E.O. (1994), "Estimating and Interpreting Forward Interest Rates: Sweden 1992-1994," IMF Working Paper No. WP/94/114.

[44] Svensson, Lars E.O. (1996a), "Comment on 'How Should Monetary Policy Respond to Shocks while Maintaining Long-run Price Stability'," forthcoming in Achieving Price Stability, Federal Reserve Bank of Kansas City.

[45] Svensson, Lars E.O. (1996b), "Inflation Targeting: Extensions," Working Paper, IIES.

[46] Svensson, Lars E.O. (1996c), “Optimal Inflation Targets, 'Conservative' Central Banks, and Linear Inflation Contracts," revision of NBER Working Paper No. 5251, September 1995. American Economic Review, forthooming.

[47] Svensson, Lars E.O. (1996d), "Price Level Targeting vs. Inflation Targeting," NBER Working Paper No. 5719.

[48] Tabellini, Guido (1995), "Towards More Effective Monetary Policy: Concluding Remarks," presented at the VII International Conference, Bank of Japan, October 1995.

[49] Taylor, John B. (1993), "Discretion versus Policy Rules in Practice," Carmegie-Rochester Conference Series on Public Policy 39, 195-214.

[50] Taylor, John B. (1996a), "How Should Monetary Policy Respond to Shocks while Maintaining Long-run Price Stability," forthcoming in Achieving Price Stability, Federal Reserve Bank of Kansas City. 
[51] Taylor, John B. (1996b), "Policy Rules as a Mesns to a More Effective Monetary Policy," Discussion Paper No. 449, Center for Economic Policy Research, Stanford University.

[52] von Hagen, Jurgen (1995), "Inflation and Monetary Targeting in Germany," in Leiderman and Svensson (1995), 107-121.

[53] von Hagen, Jügen (1996), "Monetary Policy and Institutions in the EMU," paper written for the Swedish Government Commission on EMU.

[54] Walsh, Carl E. (1993), "When Should Central Bankers Be Fired?", Working Paper, University of California at Santa Cruz.

[55] Walsh, Carl E. (1995a), "Announcements, Performance Measures and Optimal Central Bank Incentives," Working Paper, University of California at Santa Cruz.

[56] Walsh, Carl E. (1995b), "Optimal Contracts for Independent Central Bankers," American Economic Review 85, 150-167.

[57] Woodford, Michael (1994), "Nonstandard Indicators for Monetary Policy: Can Their Usefulness Be Judged from Forecasting Regressions?" in N. Gregory Mankiw, ed., Monetary Policy, University of Chicago Press, Chicago. 